\title{
Tension-Free Vaginal Tape and Autologous Rectus Fascia Pubovaginal Sling for the Treatment of Urinary Stress Incontinence: A Medium-Term Follow-Up
}

\author{
Farzaneh Sharifiaghdas Nassrin Mortazavi \\ Department of Urology, Shaheed Labbafinejad Medical Center, Urology and Nephrology Research Center, \\ Shaheed Beheshti Medical University, Tehran, Iran
}

\section{Key Words}

Tension-free vaginal tape $\cdot$ Pubovaginal sling $•$ Urinary

stress incontinence

\begin{abstract}
Objectives: To compare two different procedures, tensionfree vaginal tape (TVT) and autologous rectus fascia sling, according to their medium-term subjective and objective outcomes and satisfaction rates in the treatment of urinary stress incontinence in women. Subjects and Methods: One hundred women with type II urinary stress incontinence were randomized to be treated with either TVT or autologous rectus fascia sling. They were evaluated by means of a cough-induced stress test, 1-hour pad test, Incontinence Impact Questionnaire (IIQ), and urodynamic study. They were reevaluated postoperatively every 6 months, and the collected data of more than 1 year's follow-up were compared with preoperative assessments. Results: All patients completed the full 6-month postoperative assessment. However, of the 100 patients, only 61 ( 25 in the TVT and 36 in the sling group) were followed for more than 1 year. Mean follow-up time was 38.5 and 40 months in the TVT and sling group, respectively. Objective cure was achieved in $22(88 \%)$ of the TVT group and in $30(83 \%)$ of the sling group $(p=0.78)$ using a cough-induced stress test, and in 76 and $75 \%$ of the women in the TVT versus sling group ( $p=0.83)$, respectively, us-
\end{abstract}

\section{KARGER}

Fax +4161306 1234

E-Mail karger@karger.ch

www.karger.com (c) 2008 S. Karger AG, Basel

1011-7571/08/0173-0209\$24.50/0

Accessible online at:

www.karger.com/mpp ing a 1-hour pad test. Postoperative mean IIQ scores were 44.3 (range 35.5-61.5) and 48.5 (range 38.5-69.7) in the TVT versus sling group $(p=0.46)$. Five $(20 \%)$ and $11(30 \%)$ of the TVT and sling group, respectively, reported some changes in the voiding pattern or posture at more than 1 year's followup. Conclusion: There is no significant difference between the TVT and autologous rectus fascia sling procedures in the treatment of urinary stress incontinence at medium-term follow-up. There were changes in the voiding pattern for patients in both groups at more than 1 year postoperatively, which were not evident at early follow-up.

Copyright $\odot 2008$ S. Karger AG, Basel

\section{Introduction}

Urinary stress incontinence (USI) is a highly prevalent disorder resulting from weak urethral closure mechanisms $[1,2]$. Urinary incontinence affects a large proportion of adult women and is associated with considerable distress and social disability [1]. Initial treatment should include nonsurgical options such as behavioral changes and pelvic floor muscle training. Surgical procedures are more likely to cure USI than nonsurgical methods, but are associated with more adverse events [3].

Sling procedures, especially those called tension free, have been introduced with good long-term success and 
low complication rates; however, they still cause problems due to either an excess or a lack of tension that produces voiding difficulties or urinary leakage persistence, respectively [4].

Since Ulmsten introduced the tension-free vaginal tape in 1995 [5], it has become a popular method for surgical treatment of urodynamically proven USI [6]. The fascial sling is an effective operative technique in patients who have undergone previous operations for incontinence $[3,7,8]$.

We herein report our experience with two surgical techniques, i.e. tension-free vaginal tape (TVT) and autologous rectus fascia sling, and compare them at a medium-term follow-up.

\section{Subjects and Methods}

Between 2000 and 2004, 100 patients with USI were prospectively randomized (single-blind study) at a single institute (Shaheed Labbafinejad, Tehran) into either TVT $(\mathrm{n}=48)$ or autologous rectus fascia pubovaginal sling $(\mathrm{n}=52)$.

All patients underwent physical examination including stress test. The degree of pelvic organ prolapse was assessed and graded according to Baden et al. [9]. Basal laboratory investigations (complete blood count, renal and liver function tests, serum electrolytes, urine analysis and culture) were requested. According to the advice of the local Ethics Committee, plain abdominal radiography, urinary tract ultrasound and cystourethroscopy were performed in all patients to rule out other problems, such as stones or neoplasms. Multichannel urodynamics were performed in all patients. The degree of hypermobility was documented. Urodynamic study comprised medium-fill water cystometry $(50 \mathrm{ml}$ per minute) using a dual-lumen 8 -french catheter. The technique, definitions and units of urodynamic measure conform to the standard proposed by the International Continence Society [10] and the patients were allowed to void in the sitting position in privacy.

Inclusion criteria were as follows: a history of USI, 1-hour pad test (more than 2-gram leak), objective positive cough (effort or exertion)-induced stress test, normal cystourethroscopy and multichannel urodynamic confirmation of type II USI (abdominal leak point pressure of $60-90 \mathrm{~cm} \mathrm{H}_{2} \mathrm{O}$ ), urethral hypermobility and a competent bladder neck [11].

Exclusion criteria were a history of more than 3 episodes of urinary tract infections during the past 2 years, other gynecological problems which might affect the result of surgery or need simultaneous repairs such as high-grade uterine prolapse, highgrade rectocele and enterocele, cystocele of equal to or more than grade II, abnormal filling phase of urodynamic study (evidence of uninhibited bladder contraction, low capacity or low compliance), low flow rates (lower than $15 \mathrm{ml} / \mathrm{s}$ ), residual urine of more than $100 \mathrm{ml}$, trabeculated bladder mucosa on cystourethroscopy, a history of major pelvic trauma, and fractures that might negatively affect urethral function.

All preoperative parameters were recorded by a single experienced female urologist (F.S.). A detailed history was obtained, in- cluding the patient's age, menopausal status, parity, comorbid medical conditions, pelvic surgery, and incontinence, based on the Incontinence Impact Questionnaire (IIQ) of Shumaker et al. [12]. Women with mixed urinary incontinence (sensory urgency and urge incontinence) were not excluded as long as their urodynamic studies showed normal capacity, normal compliance and stable bladder. The study was approved by the local research Ethics Committee and informed consent was obtained after full explanation of the study. Surgery was only offered if conservative therapy had failed. The trial was independent of any industry sponsorship and involvement. Randomization was done using sealed, opaque envelopes. All procedures were performed by a single surgeon (F.S.A.), experienced in both techniques after a pilot study of at least 15 cases of TVT and 20 of sling.

Preoperative information was obtained from preprinted operative reports completed by the surgeon's assistant, anesthesiologist, and nurse. This included the type of anesthesia, operative time (incision to closure), estimated blood loss (0-100, 100-250, and $>250 \mathrm{ml}$ ), and bladder penetration (one or both sides).

Patients were observed for detection of cure and potential complications at 2 weeks and 1, 3 and 6 months after surgical treatment. Urine culture and urinary tract ultrasound (to evaluate possible unrecognized bladder penetration) were done at every visit. Reassessment was performed 12 months postoperatively as well as annually thereafter, and at the last self-visit of the patient. Urine culture, renal ultrasound and urine flowmetry were repeated. Objective cure was defined as negative cough-induced stress test with a full bladder (at least $250 \mathrm{ml}$ filled) in the lithotomy and standing position, and a 1-hour pad test lower than or equal to $2 \mathrm{~g}$. The amount of increasing weight of the pad was not compared pre- and postoperatively in each patient. Subjective cure was defined as the mean IIQ score in each group. According to the IIQ, a score less than 50 represents a good quality of life, between 50 and 70 moderate quality of life, and greater than 70 poor quality of life.

Women were asked to describe their satisfaction on a visual analogue scale of $0-10$, whether or not they would have the procedure repeated if their incontinence returned, and whether or not they would recommend the procedure to a friend. A visual analogue scale of 8-10 and positive answers to the other two questions were defined as satisfaction.

The procedure was performed on an in-patient setting under spinal anesthesia in both groups. The patient was secured in the lithotomy position and the genitalia and lower abdomen were prepared and draped in a sterile manner. The TVT procedure was performed as described by Ulmsten et al. [6]. In the sling group, a transverse Pfannenstiel incision was made, and a strip of anterior rectus fascia sheath with a size of approximately $1-1.5 \mathrm{~cm} \times$ $6 \mathrm{~cm}$ in diameter was harvested. Two parallel longitudinal incisions of about $1-1.5 \mathrm{~cm}$ were made in the anterior vaginal wall mucosa lateral to the bladder neck and proximal urethra, and a submucosal tunnel was created. The harvested graft was transferred to the vaginal submucosal tunnel. The two ends were sutured by vicryl 0 and brought to the retropubic area, and sutured to each other with no tension (2-3 fingers inserted beneath the suprapubic knot). The anterior wall of the vagina was checked to prevent overcorrection (the anterior vaginal wall should not move to the superior or posterior directions).

The bladder was filled with $250 \mathrm{ml}$ of normal saline and checked for penetration in each needle or instrument passage by 
Table 1. Patients' demographic and clinical characteristics

\begin{tabular}{lccc}
\hline & TVT $(\mathrm{n}=25)$ & Sling $(\mathrm{n}=36)$ & $\mathrm{p}$ \\
\hline Mean age, years & $49.1(32-68)$ & $55(34-70)$ & 0.75 \\
Mean parity & $3(2-8)$ & $3(2-8)$ & 0.5 \\
Hysterectomy & $9(36)$ & $9(25)$ & 0.5 \\
Previous incontinence surgery & $10(40)$ & $13(36)$ & 0.96 \\
Sensory urge incontinence & $13(55)$ & $12(33)$ & 0.23 \\
Preoperative IIQ score & $61.2(41.9-79.2)$ & $65.3(48.1-81.4)$ & \\
\hline
\end{tabular}

Figures in parentheses indicate percentages or ranges.

Table 2. Operative details of patients

\begin{tabular}{lccc}
\hline & TVT $(\mathrm{n}=25)$ & Sling $(\mathrm{n}=36)$ & $\mathrm{p}$ \\
\hline $\begin{array}{l}\text { Perioperative } \\
\text { Mean duration of operation, min }\end{array}$ & $45(30-70)$ & $80(50-180)$ & 0.01 \\
Bladder penetration & $6(24)$ & $2(8)$ & 0.05 \\
Bleeding $(\geq 250 \mathrm{ml})$ & $1(4)$ & $1(5)$ & 1.00 \\
Mean catheterization time, days & $1.3(1-5)$ & $4.6(3-6)$ & 0.001 \\
Mean hospital stay, days & $2(1-5)$ & $5(3-7)$ & 0.001 \\
\hline Operative complications & & & \\
6- to 12-month follow-up & & & \\
$\quad$ Residual urine $>100$ ml & $1(4)$ & $2(14)$ & 0.4 \\
$\quad$ Release of sling patient & $1(4)$ & & 1.00 \\
More than 1-year follow-up & & & \\
$\quad$ Self-reported de novo urge incontinence & $1(4)$ & $11(31)$ & 0.1 \\
$\quad$ Changes in voiding pattern & $5(20)$ & \\
\hline
\end{tabular}

Figures in parentheses indicate percentages or ranges.

a 0 -degree and 70-degree optic lens. A 16-french Foley catheter was left in situ. The urethral catheter was removed on the first postoperative day in the TVT and 3-5 days postoperatively in the sling group, according to the patient's surgical wound condition (pain, healing of suprapubic and vaginal wound) and overall cooperation. In the case of bladder penetration, the urethral catheter remained in situ for 6-7 days in both groups.

Patients were asked to urinate two times before being discharged from the hospital and on each occasion, residual urine was measured by clean catheterization (the result of residual urine measurement by ultrasound has been false more often than with catheterization in our center [unpublished data]). They were discharged if the residual volume was less than $100 \mathrm{ml}$, and/or the voided volume was twice that of the residual volume.

Postoperative information of patients was analyzed if they agreed to a full assessment more than 1 year after surgery. Data were analyzed with SPSS software (Statistical Package for the Social Sciences, version 11.5, SSPS Inc., Chicago, Ill., USA) using the $\chi^{2}$ test, Fisher exact test, and independent sample test.

A value of $\mathrm{p}<0.05$ was considered statistically significant, and the assumed confidence interval was $95 \%$.

TVT versus Rectus Fascia Sling for the Treatment of USI

\section{Results}

All patients completed the full 6-month postoperative assessment. However, only 61 out of 100 were followed for more than 1 year. Of the 39 patients lost to follow-up, 16 were due to the distance and expense of travel, 12 were age-related and 11 were because of dissatisfaction with the surgical result (5 in the TVT and 6 in the sling group), as reported by telephone interview. The demographic and clinical characteristics of the patients are shown in table 1 . There were no differences in age, history of failed previous anti-incontinence procedure, history of abdominal hysterectomy, and coexisting symptoms of urgency and urge incontinence between the two groups. The mean follow-up time was 38.5 (range 14-52) and 40 (range $15-54)$ months in the TVT versus sling group $(\mathrm{p}=0.65)$.

The operation outcomes are summarized in table 2 . The mean operative time was similar in both groups $(\mathrm{p}=$ 0.01 ). The bladder was more commonly penetrated in the 
TVT group ( $\mathrm{p}=0.05)$, which did not change the surgical plan.

More than $100 \mathrm{ml}$ of intraoperative bleeding occurred in $6(24 \%)$ and 11 (30\%) in the TVT and sling groups, respectively, during the passage of instruments from the Retzius space, but in each group only 1 patient needed a blood transfusion intraoperatively due to more than 250 $\mathrm{ml}$ hemorrhage. Blood transfusion was made according to the judgment of the anesthesiologist. Hemorrhage was independent of bladder penetration. None of the patients received postoperative transfusion due to a dramatic decrease in the level of hemoglobin. The mean duration of catheterization $(\mathrm{p}<0.001)$ and hospitalization $(\mathrm{p}<0.001)$ was lower in the TVT group than in the sling group. Residual urine more than $100 \mathrm{ml}$ and the need for intermittent self-catheterization was similar in both groups $(\mathrm{p}=$ $0.4), 4$ weeks after surgery. Surgical revision was done in 1 and 2 patients of the TVT and sling groups, respectively. Residual urine decreased gradually to lower than 100 $\mathrm{ml}$ in the remaining 2 patients of the sling group until 1 year postoperatively without the need for surgical intervention. Sensory urgency and urge incontinence improved in 8 and remained in 5 patients in the TVT group, and correspondingly improved in 5 and remained in 7 in the sling group.

De novo urge incontinence (self-reported by the patient and not urodynamically proven to be motor urge incontinence) was equal in both groups ( $\mathrm{p}=0.1)$. Of $8 \mathrm{pa}-$ tients with de novo urge incontinence in the sling group, only 2 complained of voiding difficulties and residual urine (50 and $70 \mathrm{ml})$.

Objective cure rate by the 1-hour pad test was 76 and $72 \%$ in the TVT and sling group, respectively $(\mathrm{p}=0.83)$, and by the negative cough-induced stress test, it was 88 and $83 \%$ in the TVT and sling group, respectively ( $\mathrm{p}=$ $0.9)$.

Subjective cure as determined by mean IIQ scores was 44.3 (range 35.2-61.5) in the TVT and 48.5 (range 38.5$69.7)$ in the sling group $(\mathrm{p}=0.46)$. Fifteen $(72 \%)$ of the TVT group and 20 (55\%) of the sling group were satisfied with the operation $(\mathrm{p}=0.3)$.

Comparison between preoperative and postoperative data on uroflowmetry (in the sitting position) showed some decrease in the maximum flow rate of both groups $(31 \pm 12$ to $27 \pm 8.7 \mathrm{ml} / \mathrm{s}$ in the TVT and $30.2 \pm 10.8$ to $26.7 \pm 6.2 \mathrm{ml} / \mathrm{s}$ in the sling group; $\mathrm{p}<0.05$ ), but there was no statistically significant difference between the two groups postoperatively $(\mathrm{p}=0.2)$. Five $(20 \%)$ patients in the TVT and 11 (31\%) in the sling group reported that they had gradually noted some changes in the pattern of voiding that was not evident in the early (first 6-12 months) follow-up, but it was not a constant phenomenon $(\mathrm{p}=0.5)$.

Self-reported changes were occasional feeling of sudden transient stop in the urinary stream, need for a Credé maneuver at the end of stream, or need to change posture (from squatting to sitting, from sitting to semi-standing or bending forward) to help empty the bladder or feel comfortable. The mean maximum flow rate of these 16 patients was within normal limits $(23.5$ and $21.6 \mathrm{ml} / \mathrm{s}$ in the TVT vs. sling group) in the sitting position. Of these 16 , only 2 patients in the sling group had a residual urine $\geq 50 \mathrm{ml}$ (50 and $70 \mathrm{ml}$ ).

Postoperative complication included urinary retention and high residue $(>100 \mathrm{ml})$ in 1 and 2 patients in the TVT and sling group, respectively. The release of suprapubic anchoring knots in 1 and combined vaginoabdominal urethrolysis in another patient of the sling group were performed 1 and 6 months postoperatively. Suprapubic incisional hernia was repaired in 1 patient in the sling group 8 months after the surgery. Another patient in the TVT group also suffered from left-side suprapubic hernia in the route of needle passage while awaiting repair. The upper tract ultrasound results remained unchanged in both groups.

\section{Discussion}

The search for the optimal surgical technique for USI is still under way. There are over 100 different surgical procedures for the treatment of USI [14]. Based on the available data $[3,7,8]$, colposuspension, pubovaginal sling and the newer mid-urethral synthetic slings are the most effective surgical treatments. TVT $[5,14]$ is used to correct USI by providing a firm backboard or 'hammock' for the urethra to rest on when intra-abdominal pressure increases. There are early reports on the efficacy of TVT on heterogenous types of USI in female patients [15-17]. In order to draw a more precise and practical conclusion, we tried to limit our study to the patients with type II USI (abdominal leak point pressure $=60 \mathrm{~cm} \mathrm{H}_{2} \mathrm{O}$ to $90 \mathrm{~cm}$ $\mathrm{H}_{2} \mathrm{O}$ ), which is the most common type. Also, for more precise exclusion criteria, we performed cystourethroscopy in all patients, although it is not routinely performed in the majority of studies and is considered only for patients with a history of previous pelvic surgery.

We elected to use autologous rectus fascia because a high failure rate has been reported using cadaveric donor fascia [18]. There are many studies evaluating TVT and 
sling methods, but the majority are retrospective observational studies and not randomized controlled trials [18-20]. However, there are a few randomized studies comparing TVT with other procedures [21-24]. AbdelFattah et al. [21] have compared TVT with pelvicol pubovaginal sling in 142 patients and reported equal success rates $(90 \%)$ in the 3 -year follow-up for both, but one main criticism of the study was the subjective assessment of the success rate from a questionnaire answered by patients. Valpas et al. [22] compared TVT with laparoscopic mesh colposuspension and reported success rates of 85.7 and $56.9 \%$, respectively, using an objective 24 -hour pad test. However, the follow-up was only 1 year and the surgery was performed in 6 medical centers by different surgeons in contrast to 1 surgeon in this study. Cholhan and Lotze [23] reported 91.7 and $88.5 \%$ success rates for TVT and conventional sling methods in a 2-year follow-up in 48 patients. Wadie et al. [24] compared TVT with autologous fascial sling at short-term follow-up and reported equal success rates for both procedures. Our study did not reveal any statistically significant difference between these two surgical methods, although the cure rates were lower and the follow-up was longer compared to the reports by Cholhan and Lotze [23] and Wadie et al. [24].

In a Cochrane study, Bezerra et al. [25] evaluated the effects of traditional suburethral slings on pure and mixed stress incontinence in comparison with other management options (13 trials, which included 760 women, of whom 627 were treated with suburethral slings). They concluded that reliable evidence by which to judge whether or not suburethral slings are better than other surgical or conservative management options is currently not available.

The reported rate of de novo urge incontinence varies between 2.2 and $15 \%$ [26, 27]. As we have not reported postoperative urodynamic findings, we cannot differen- tiate whether it is of sensory or motor type, although de novo urge incontinence in our study was reported in $22 \%$ of the sling group; however, this was not statistically different from the TVT group. Of 8 patients with urge incontinence in the sling group, only 2 complained of voiding difficulty and residual urine $(<100 \mathrm{ml})$. It is not clear whether placement of the rectus fascia at the level of the proximal urethra may trigger mechanisms resulting in irritative bladder symptoms without obvious changes in urinary stream. Self-reported changes in the pattern of voiding or the need for changing posture during voiding was a new finding for us since the patients claimed it gradually appeared and was not evident at early (6-12 months) follow-up. It is not clear whether this should be recognized as a voiding disorder or not. Another study is ongoing to evaluate multichannel urodynamics and uroflowmetry in different positions in all the patients. Using urodynamic evaluation to identify functional obstruction after TVT has been done in several studies [27-31] in which an increase in maximum urethral closure pressure, decreased peak and mean flow rates, and increased voiding detrusor, mean detrusor pressure, and mean urethral resistance have been observed.

It seems that late voiding dysfunction ( $\geq 1$ year's follow-up) and its variants is an underreported postoperative complication which needs more evaluation.

\section{Conclusion}

There was no statistical difference in terms of objective and subjective cure rates between TVT and autologous rectus fascial sling procedures in the treatment of type II USI. Self-reported changes in voiding pattern or posture at more than 1-year follow-up were not evident at early follow-up.

\section{References}

1 Ananias C, Diakno MO: Epidemiology of female incontinence; in Raz S (ed): Raz Female Urology. Philadelphia, Saunders, 1996, pp 73-79.

2 Price N, Jackson S: Clinical audit of the use of tension-free vaginal tape as a surgical treatment for urinary stress incontinence, set against NICE guidelines. J Obstet Gynaecol 2004;24:534-538.

3 Nygaard IE, Heit M: Stress urinary incontinence. Obstet Gynecol 2004;104:607-620.
4 Sousa-Escandon A, Lema Grille J, Rodriguez Gomez JI, Rios Tallon L, Uribarri Gonzalez C, Marques-Queimadelos A: Externally readjustable device to regulate sling tension in stress urinary incontinence: preliminary results. J Endourol 2003;17:515-521.

5 Ulmsten U, Petros P: Intravaginal sling plasty (IVS): an ambulatory surgical procedure for treatment of female urinary incontinence. Scand J Urol Nephrol 1995;529:750754 .
TVT versus Rectus Fascia Sling for the Treatment of USI
Med Princ Pract 2008;17:209-214 
8 Chaikin DC, Rosenthal J, Blaivas JG: Pubovaginal sling for all types of stress urinary incontinence: long-term analysis. J Urol 1998;160:1312-1315.

$>9$ Baden WF, Walker TA, Lindsey JH: The vaginal profile. Tex Med 1968;64:56-58.

-10 Abrams P, Cardozo L, Fall M, Griffiths D, Rosier P, Ulmsten U, van Kerrebroeck P, Victor A, Wein A: The standardization of terminology of lower urinary tract function: report from Standardization Sub-committee of the International Continence Society. Neurourol Urodyn 2002;21:167-178.

-11 Mc Guire EJ, Cespedes RD, O’Connell HE: Leak-point pressures. Urol Clin North Am 1996;23:253-262.

-12 Shumaker SA, Wyman JF, Uebersax JS, McClish D, Fantl JA: Health-related quality of life measures for women with urinary incontinence: the Incontinence Impact Questionnaire and the Urogenital Distress Inventory. Continence Program in Women (CPW) Research Group. Qual Life Res 1994;3:291306.

13 Bealieu S, Collet JP, Tu LM, Macrammalla E, Wood-Dauphinee S, Corcos J: Performance of the Incontinence Impact Questionnaire in Canada. Can J Urol 1999;6:692-699.

14 Corcos J, Behlouli H, Beaulieu S: Identifying cut-off scores with neural networks for interpretation of the incontinence impact questionnaire. Neurourol Urodyn 2002;21:198203.

15 Bros M, Czajkowski K, Kornacki P: Analysis of complications of the tension-free vaginal tape procedure for surgical treatment of female urinary incontinence. Ginekol Pol 2003;74:930-936.
16 Soulie M, Cuvillier X, Benaissa A, et al: The tension-free transvaginal tape procedure in the treatment of female urinary stress incontinence. A French prospective multicenter study. Eur Urol 2001;39:709-715.

17 Jeffry L, Deval B, Birsan A, Soriano D, Darai E: Objective and subjective cure rates after tension-free vaginal tape for treatment of urinary incontinence. Urology 2001;59:702706.

18 Fitzgerald MP, Edwards SR, Fenner D: Medium-term follow-up on use of freeze-dried, irradiated donor fascia for sacrocolpopexy and sling procedures. Int Urogynecol J Pelvic Floor Dysfunct 2004;15:238-242.

19 Allahdin S, McKinley CA, Mahmood TA: Tension-free vaginal tape: a procedure for all ages. Acta Obstet Gynecol Scand 2004;83: 937-940.

20 Cetinel B, Demirkesen O, Onal B, Akkus E, Alan C, Can G: Are there any factors predicting the cure and complication rates of tension-free vaginal tape? Int Urogynecol J Pelvic Floor Dysfunct 2004;15:183-193.

21 Abdel-Fattah M, Barrington JW, Arunkalaivanan AS: Pelvicol pubovaginal sling versus tension-free vaginal tape for treatment of urodynamic stress incontinence: a prospec tive randomized three-year follow-up study. Eur Urol 2004;46:629-635.

22 Valpas A, Kivela A, Penttinen J, Kujansuu E, Haarala M, Nilsson CG: Tension-free vaginal tape and laparoscopic mesh colposuspension for stress urinary incontinence. $\mathrm{Ob}$ stet Gynecol 2004;104:42-49.

23 Cholhan HJ, Lotze PM: Voiding function after a modified no-tension pubovaginal sling. Int Urogynecol J Pelvic Floor Dysfunct 2004; 15:249-256.
24 Wadie BS, Edwan A, Nabeeh AM: Autologous fascial sling vs polypropylene tape at short-term follow-up: a prospective randomized study. J Urol 2005;174:990-993.

25 Bezerra CA, Bruschini H, Cody DJ: Traditional suburethral sling operations for urinary incontinence in women. Cochrane Database Syst Rev 2005;20:CD001754.

-26 Nilsson CG, Falconer C, Rezapour M: Sevenyear follow-up of the tension-free vaginal tape procedure for treatment of urinary incontinence. Obstet Gynecol 2004;104:12591262.

27 Sander P, Møller LM, Rudnicki PM, Lose G: Does the tension-free vaginal tape procedure affect the voiding phase? Pressure-flow studies before and 1 year after surgery. BJU Int 2002;89:694-698.

28 Wang KH, Wang KH, Neimark M, Davila GW: Voiding dysfunction following TVT procedure. Int Urogynecol J Pelvic Floor Dysfunct 2002;13:353-357.

29 Lukacz ES, Luber KM, Nager CW: The effects of the tension-free vaginal tape on voiding function: a prospective evaluation. Int Urogynecol J Pelvic Floor Dysfunct 2004;15: 32-38.

30 Mazouni C, Karsenty G, Bretelle F, Bladou F, Gamerre M, Serment G: Urinary complications and sexual function after the tensionfree vaginal tape procedure. Acta Obstet Gynecol Scand 2004;83:955-961.

31 Vervest HA, Bisseling TM, Heintz AP, Schraffordt Koops SE: The prevalence of voiding difficulty after TVT, its impact on quality of life, and related risk factors. Int Urogynecol J Pelvic Floor Dysfunct 2007;18: 173-182. 